\title{
Per-oral pancreatoscopy with intraductal lithotripsy for difficult pancreatic duct stones: a systematic review and meta-analysis
}

\section{다)(1) $\odot(9)$}

\author{
Authors \\ Thomas R. McCarty ${ }^{1}$, Zain Sobani², Tarun Rustagi² \\ Institutions \\ 1 Division of Gastroenterology, Hepatology and \\ Endoscopy, Brigham and Women's Hospital, Harvard \\ Medical School, Boston, Massachusetts, United States \\ 2 Division of Gastroenterology and Hepatology, University \\ of New Mexico, Albuquerque, New Mexico, United \\ States
}

submitted 28.4.2020

accepted after revision 14.7 .2020

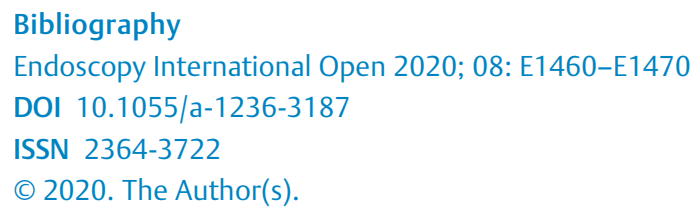
Commons Attribution-NonDerivative-NonCommercial License, permitting copying and reproduction so long as the original work is given appropriate credit. Contents may not be used for commecial purposes, or adapted, remixed, transformed or built upon. (https://creativecommons.org/licenses/by-nc-nd/4.0/)

Corresponding author

Tarun Rustagi, MD, Division of Gastroenterology and Hepatology, University of New Mexico, MSC10 5550, 1 University of New Mexico, Albuquerque NM 87131, Mexico Fax: +1- 505-272-9751

tarunrustagi06@gmail.com

Supplementary material is available under https://doi.org/10.1055/a-1236-3187

\section{ABSTRACT}

Background and study aims Per-oral pancreatoscopy (POP) with intraductal lithotripsy via electrohydraulic lithotripsy (EHL) or laser lithotripsy (LL) facilitates optically-guided stone fragmentation of difficult pancreatic stones refractory to conventional endoscopic therapy. The aim of this study was to perform a systematic review and meta-analysis to evaluate the efficacy and safety of POP with intraductal lithotripsy for difficult pancreatic duct stones.

Methods Individualized search strategies were developed in accordance with Preferred Reporting Items for Systematic Reviews and Meta-Analyses and Meta-analysis of Observational Studies in Epidemiology guidelines. This was a cumulative meta-analysis performed by calculating pooled proportions with rates estimated using random effects models. Measured outcomes included pooled technical success, complete or partial stone fragmentation success, complete duct clearance after initial lithotripsy session, and adverse events (AEs).

Results Ten studies ( $n=302$ patients; $67.72 \%$ male; mean age $55.10 \pm 3.22$ years) were included with mean stone size of $10.66 \pm 2.19 \mathrm{~mm}$. The most common stone location was in the pancreatic head (66.17\%). Pooled technical success was $91.18 \%$ with an overall fragmentation success of $85.77 \%$. Single lithotripsy session stone fragmentation and pancreatic duct clearance occurred in $62.05 \%$ of cases. Overall, adverse events were reported in $14.09 \%$ of patients with post-procedure pancreatitis developing in $8.73 \%$. Of these adverse events, $4.84 \%$ were classified as serious. Comparing POP-EHL vs POP-LL, there was no significant difference in technical success, fragmentation success, single session duct clearance, or AEs $(P>0.0500)$.

Conclusions Based on this systematic review and meta-analysis, POP with intraductal lithotripsy appears to be an effective and relatively safe procedure for patients with difficult to remove pancreatic duct stones.

\section{Introduction}

Completely or partially obstructing pancreatic duct stones are a common complication during the natural course of chronic calcific pancreatitis and may contribute to additional pain and acute on chronic pancreatitis through an increase in intraductal pressure [1-4]. In fact, as many as $90 \%$ of patients with chronic pancreatitis are identified as having pancreatic duct stones during long-term follow-up; however, it is important to note these 
stones may be found incidentally in a majority of patients [5]. Stones typically develop proximal to pancreatic duct strictures, and for those individuals with symptomatic pancreatic duct stones, endoscopic removal is generally recommended to reduce recurrent flares and pain. Endoscopic strategies typically are less invasive than traditional surgery and more likely to be successful in cases with a small stone burden and stone location isolated within the main pancreatic duct $[4,6,7]$. However, despite endoscopic management being a preferred strategy for removal of pancreatic duct stones, removal may be challenging - especially compared to more conventional biliary stones.

Underscoring this therapeutic dilemma for the endoscopist is the fact that there are multiple endoscopic techniques available, including: pancreatic sphincterotomy, balloon sphincteroplasty, extraction baskets, rat tooth forceps-assisted stone retrieval, pancreatic stent placement, mechanical lithotripsy, and per-oral pancreatoscopy (POP)-assisted intraductal lithotripsy [8]. Of these, mechanical lithotripsy and POP-assisted intraductal lithotripsy are typically reserved for difficult pancreatic duct stones, refractory to basic endoscopic retrograde cholangiopancreatography (ERCP) stone extraction techniques involving pancreatic sphincterotomy, balloon sphincteroplasty, and extraction balloons and baskets. While few comparative studies exist, the European Society of Gastrointestinal Endoscopy (ESGE) suggests endoscopic therapy and/or mechanical extracorporeal shockwave lithotripsy (ESWL) be the first-line treatment for painful uncomplicated chronic pancreatitis with an obstructed main pancreatic duct in the head/body of the pancreas (weak recommendation, low quality evidence) [9]. Despite this guidance, intracorporeal lithotripsy using electrohydraulic lithotripsy (EHL) or laser lithotripsy (LL) under POP may be considered after ESWL has failed, mostly viewed as a secondline strategy due to the procedure's technical complexity and special equipment required $[9,10]$.

Yet despite these guidelines and summary recommendations, there remains a paucity of data to truly assess the feasibility and effectiveness of POP with intraductal lithotripsy with variable rates of fragmentation and duct clearance rates reported. Furthermore, there remains limited literature assessing EHL versus LL with few studies comparing the two available intraductal treatment modalities. As such, the primary aim of this study was to perform a structured systematic review and metaanalysis to evaluate the efficacy and safety of POP with intraductal lithotripsy for treatment of difficult pancreatic duct stones. The secondary aim was to compare the efficacy and safety of POP-EHL versus POP-LL treatment of pancreatic duct stones.

\section{Methods}

\section{Literature search}

A comprehensive search of the literature was performed to identify articles that examined POP specifically for treatment of difficult-to-remove pancreatic duct stones. Systematic searches of PubMed, EMBASE, Web of Science, and the Cochrane Library databases were performed from inception through November 30, 2019. The following medical subject heading
(MESH) terms included: per-oral pancreatoscopy (POP), singleoperator pancreatoscopy, pancreatoscopy, endoscopic pancreatoscopy, and antegrade pancreatoscopy. For articles related to these MESH terms, subject heading search terms and title and abstract were reviewed for: pancreatic duct stones, intraductal lithotripsy, intracorporal lithotripsy, electrohydraulic lithotripsy (EHL), and laser lithotripsy (LL).

All relevant English language articles irrespective of year of publication, type of publication, or publication status were included. The titles and abstracts of all potentially relevant studies were screened for eligibility. The reference lists of studies of interest were then manually reviewed for additional articles by cross checking bibliographies. Two reviewers (TRM and ZS) independently screened the titles and abstracts of all the articles according to predefined inclusion and exclusion criteria. Any differences were resolved by mutual agreement and in consultation with the third reviewer (TR). In the case of studies with incomplete information, contact was attempted with the principal authors to obtain additional data.

\section{Study selection criteria}

This study was prospectively submitted in PROSPERO, an international database of prospectively registered systematic reviews in health and social care. The Preferred Reporting Items for Systematic Reviews and Meta-Analyses (PRISMA) statement outline and Meta-Analysis of Observational Studies in Epidemiology (MOOSE) reporting guidelines for reporting systematic reviews and meta-analyses was used to report findings (Appendix 1 and Appendix 2) [11, 12]. Full-text manuscripts as well as abstracts were considered for inclusion in this meta-analysis. Only human studies investigating the use of the POP modality for the treatment of pancreatic duct stones were included. All generations of the device were included.

Although no consensus definition exists, difficult pancreatic stones were defined by prior failure of conventional endoscopy therapy (stones that could not be extracted during prior ERCP using standard techniques including pancreatic sphincterotomy, balloon sphincteroplasty, balloon and/or basket extraction, pancreatic stent placement or attempted treatment with mechanical lithotripsy), generally agreed upon criteria based on previous literature, and study authors' definitions. Biliary duct stones or studies with both biliary and pancreatic stones were excluded if individual pancreatic duct outcomes were not reported. A study was also excluded if deemed to have insufficient data, as were review articles, editorials, and correspondence letters that did not report independent data. Case series and reported studies with $<10$ patients were excluded to minimize selection bias. Multiple published work from similar authors was evaluated for overlapping enrollment times to preserve independence of observations.

\section{Outcome measures}

The primary outcome measurement in this systematic review and meta-analysis was the efficacy and safety of POP in patients with difficult pancreatic duct stones. Efficacy and safety of pancreatoscopy was measured by overall fragmentation success rate (i. e., ability to visualize the pancreatic duct stone and per- 
form successful fragmentation) and adverse events reported. Additional markers of success included percent of complete fragmentation and pancreatic duct clearance after a single pancreatoscopy-assisted intraductal lithotripsy session. Complete or partial fragmentation and duct clearance were determined based upon intra-procedural pancreatography and/or pancreatoscopy as determined by the endoscopist. Duct clearance and successful stone removal was determined based upon pancreatography and/or pancreatoscopy after balloon and/or basket extraction and/or evidence of decompression of the pancreatic duct. Other measured outcomes included baseline patient and stone characteristics (i.e., mean age, gender, previous treatment, stone number, stone size, and stone location) as well as procedural-related characteristics (i.e., pancreatoscopy technique, type of lithotripsy, number of sessions, and procedure time).

\section{Statistical analysis}

This meta-analysis was performed by calculating pooled proportions. After appropriate studies were identified through systematic review, the individual study proportion was transformed into a quantity using the Freeman-Tukey variant of the arcsine square root transformed proportion. Then the pooled proportion was calculated as the back transform of the weighted mean of the transformed proportions, DerSimonian-Laird weights for the random effects model $[13,14]$. The pooled rates were estimated using random effects models and presented as point estimates (rates) with $95 \%$ confidence intervals [15-17]. In contrast to fixed effect models, which are used to estimate a common effect, random effect models estimate an average effect, and the variability of the effects represented by their average may have clinical implications.

For subgroup analysis and difference between EHL and LL, statistical significance for the differences between groups included the $95 \%$ confidence intervals ( $\mathrm{Cls}$ ) of the two pooled proportions considered, and the differences of proportions and $95 \% \mathrm{Cls}$ were calculated. Univariable meta-regression was performed to assess the influence of type of treatment (EHL vs $\mathrm{LL}$ ) on overall fragmentation rate, single lithotripsy session success rate, and rate of adverse events. All calculated $P$ values were 2 -sided, and $P<0.05$ was considered statistically significant. Tabular and graphical analyses were performing using Comprehensive Meta-Analysis software, version 3 (BioStat, Englewood, New Jersey, United States). Combined weighted proportions were determined by use of the Stata 15.0 software package (Stata Corp LP, College Station, Texas, United States).

\section{Risk of bias and quality assessment}

Risk of bias and quality of observational studies was evaluated using the Newcastle-Ottawa Quality Assessment Scale and Jadad score for quality of randomized trials $[18,19]$. In this study, high quality was defined as a Newcastle-Ottawa Quality Assessment Scale score of $\geq 4$ or a JADAD score of $\geq 3$. Two authors (TRM and ZS) independently extracted data and assessed the risk of bias and study quality for each of the articles. Any disagreements were resolved by discussion and consensus, and in consultation with the third reviewer (TR).

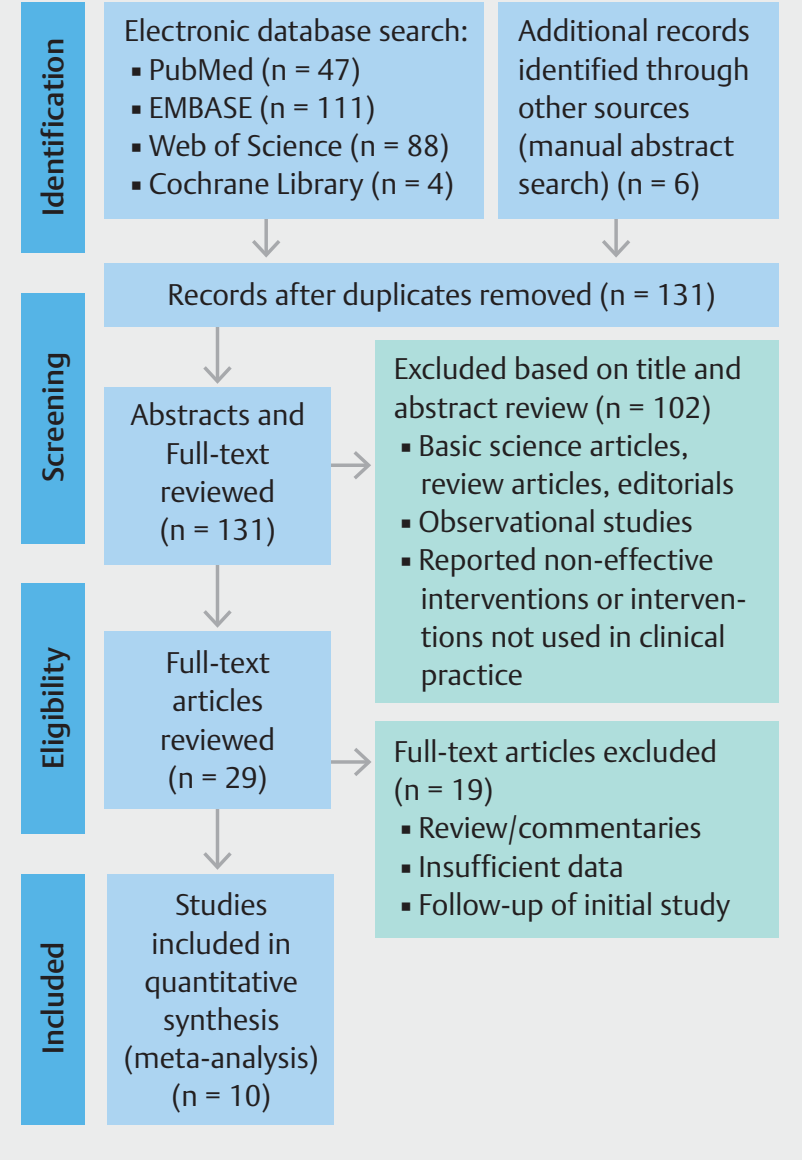

- Fig. 1 Preferred Reporting Items for Systematic Reviews and Meta-Analyses (PRISMA) flowchart of literature search results. From: Moher D, Liberati A, Tetzlaff J, Altman DG, The PRISMA Group (2009). Preferred Reporting Items for Systematic Reviews and Meta-Analyses: The PRISMA Statement. PLoS Med 6(7): e1000097. doi:10.1371/journal.pmed1000097.

\section{Investigations of heterogeneity and prediction interval}

Heterogeneity was assessed for the individual meta-analyses using the chi squared test and the 12 statistic [16]. Significant heterogeneity was defined as $P<0.05$ using the Cochran $Q$ test or $l^{2}>50 \%$, with values $>50 \%$ indicating substantial heterogeneity. Further quantification of heterogeneity was categorized based upon $R^{2}$ with values of $25 \%, 50 \%$, and $75 \%$ indicating low, moderate, and high amounts of heterogeneity, respectively. Given the use of random effects model to estimate average effect, a $95 \%$ prediction interval was calculated to determine the dispersion of effects and clearly illustrate heterogeneity in the calculated effect size [15, 20-23].

\section{Publication bias}

To assess for publication bias, a funnel plot was created and visually inspected for asymmetry and quantitatively using Egger regression testing $[24,25]$. The trim and fill method was used to correct for funnel plot asymmetry and provide an adjusted 


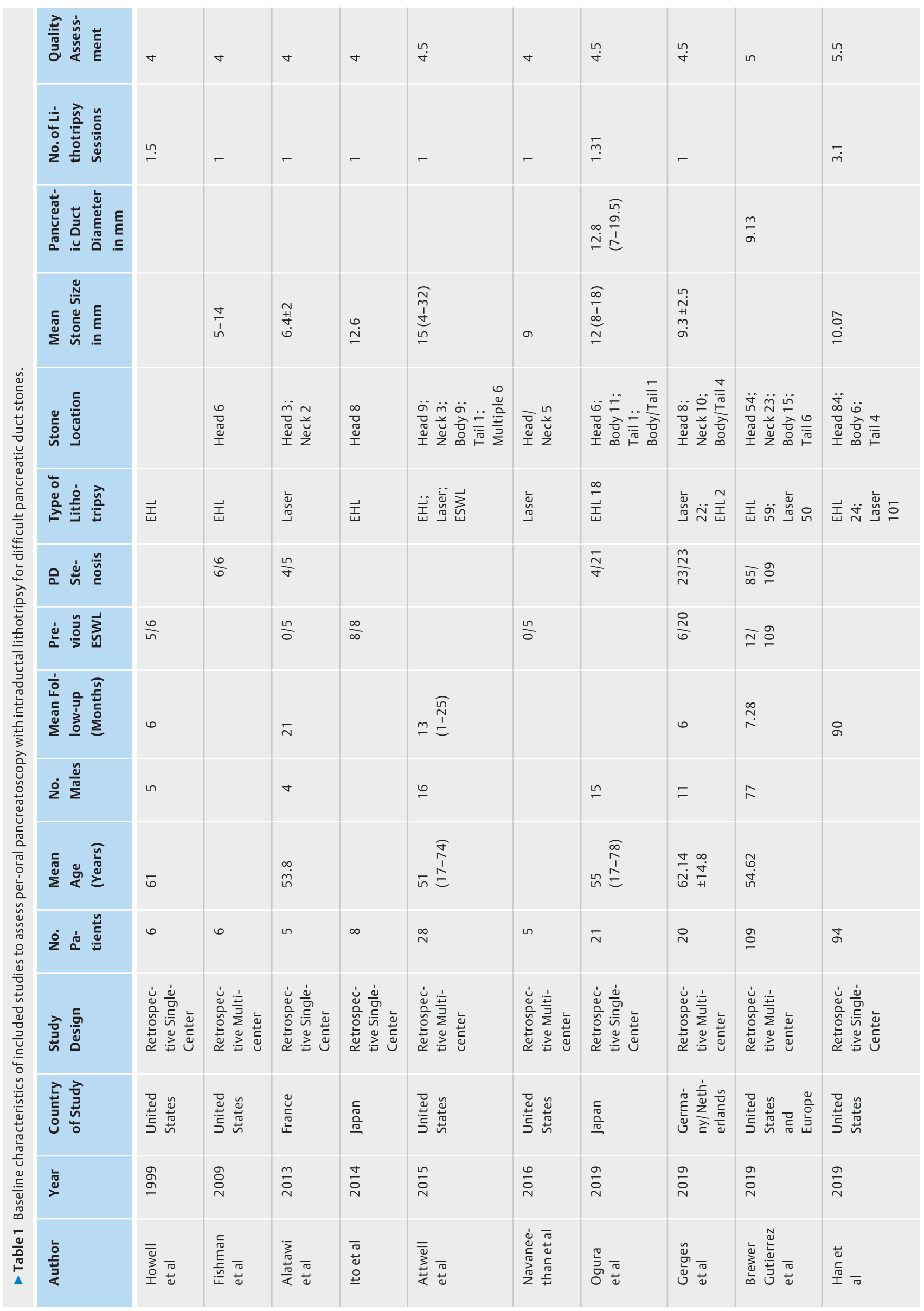


- Table2 Outcomes per-oral pancreatoscopy with intraductal lithotripsy for difficult pancreatic duct stones.

\begin{tabular}{|l|c|c|c|c|c|c|}
\hline Author & Year & $\begin{array}{c}\text { Technical } \\
\text { Success }\end{array}$ & $\begin{array}{l}\text { Clinical } \\
\text { Success }\end{array}$ & $\begin{array}{l}\text { Single Session } \\
\text { Duct Clearance }\end{array}$ & $\begin{array}{l}\text { No. Adverse } \\
\text { Events }\end{array}$ & $\begin{array}{l}\text { No. Serious } \\
\text { Adverse Events }\end{array}$ \\
\hline Powell et al & 1999 & $6 / 6$ & $5 / 6$ & $3 / 6$ & $1 / 6$ & $1 / 6$ \\
\hline Fishman et al & 2009 & $6 / 6$ & $3 / 6$ & $3 / 6$ & $0 / 6$ & $0 / 6$ \\
\hline Alatawi et al & 2013 & $5 / 5$ & $5 / 5$ & $4 / 5$ & $0 / 5$ & $0 / 5$ \\
\hline Ito et al & 2014 & $3 / 8$ & $3 / 8$ & & $2 / 8$ & $2 / 8$ \\
\hline Attwell et al & 2015 & $25 / 28$ & $25 / 28$ & $17 / 28$ & $8 / 28$ & $0 / 28$ \\
\hline Navaneethan et al & 2016 & $5 / 5$ & $4 / 5$ & $4 / 5$ & $0 / 5$ & $0 / 5$ \\
\hline Ogura et al & 2019 & $19 / 21$ & $18 / 21$ & & $1 / 21$ & $0 / 21$ \\
\hline Gerges et al & 2019 & $20 / 20$ & $19 / 20$ & $19 / 20$ & $7 / 23$ & $1 / 23$ \\
\hline Brewer Gutierrez et al & 2019 & $101 / 109$ & $98 / 109$ & $72 / 109$ & $11 / 109$ & $2 / 109$ \\
\hline Han et al & 2019 & $124 / 125$ & $124 / 125$ & $25 / 125$ & $8 / 125$ & $1 / 125$ \\
\hline ERCP, endoscopic retrograde cholangiopancreatography & & & & $1 / 21$ \\
\hline
\end{tabular}

effect [26]. The classic fail-safe test was also applied to assess risk of bias across studies.

\section{Results}

\section{Study characteristics}

A total of 10 studies ( $n=302$ patients) were included in this meta-analysis [27-36]. A PRISMA flow chart of search results is shown in $>$ Fig. 1. All studies were retrospective in nature with five multicenter studies included ( $\triangleright$ Table $1, \triangleright$ Table 2 ). EHL was exclusively studied in four studies, LL evaluated in two studies, and both modalities in four studies.

\section{Patient and procedure characteristics}

A total of 302 patients were included in this meta-analysis. Sixty-seven percent of patients were male. The mean age of patients that underwent POP with intraductal lithotripsy was $55.1 \pm 3.22$ years. The size of pancreatic duct stones treated was reported in 8 studies, with a pooled mean size of $10.66 \pm$ $2.19 \mathrm{~mm}$. In the two studies that reported mean pancreatic duct diameter, this was documented to be of $9.72 \pm 1.59 \mathrm{~mm}$. The most common location of pancreatic duct stones was in the pancreatic head $(66.17 \%)$ followed by the body (15.24\%), neck $(14.13 \%)$, and tail $(4.46 \%)$. Six studies reported patients had previously undergone ERCP with pancreatic sphincterotomy, pancreatic duct stent placement, or previous ESWL ( $\bullet$ Table 1, > Table 2). Overall, the mean number of lithotripsy sessions (regardless of type) was $2.07 \pm 1.01$ required for stone fragmentation and pancreatic duct clearance.

\section{Clinical effectiveness and safety}

POP with intraductal lithotripsy achieved an overall technical success rate of $91.18 \%\left(95 \% \mathrm{Cl}, 80.93\right.$ to $96.18 ; \mathrm{I}^{2}=60.26$; prediction interval -70.79 to 99.93 ) ( $\triangleright$ Fig. 2a). Overall stone fragmentation success was $85.77 \%\left(95 \% \mathrm{Cl}, 72.49\right.$ to $93.24 ; \mathrm{I}^{2}=$ 66.86; prediction interval -81.09 to 99.88 ) ( $\mathbf{F i g . 2 b}$ ). Com- plete fragmentation and duct clearance was achieved in $62.05 \%\left(95 \% \mathrm{Cl}, 38.29\right.$ to $81.17 ; \mathrm{I}^{2}=61.63$; prediction interval -97.78 to 99.88 ) ( $\triangleright$ Fig. 2c). Total procedure-associated adverse events were $14.09 \%\left(95 \% \mathrm{Cl}, 8.31\right.$ to $22.90 ; \mathrm{I}^{2}=52.77$; prediction interval -86.04 to 91.84$)$ with serious adverse events occurring in $4.84 \%\left(95 \% \mathrm{Cl}, 2.13\right.$ to $10.62 ; \mathrm{I}^{2}=33.09$; prediction interval -93.95 to 94.99 ) of cases ( $\boldsymbol{F}$ Fig.3a and - Fig. 3b). The most common POP-related adverse event was acute (post-ERCP) pancreatitis that occurred after $8.73 \%$ (95\% $\mathrm{Cl}, 4.50$ to $16.27 ; \mathrm{I}^{2}=28.50$; prediction interval -83.88 to 88.37 ) of cases ( $\boldsymbol{F i g} \cdot \mathbf{3 c}$ ). Sensitivity analyses limited to prospective studies were not possible given inclusion of only retrospective data.

\section{Subgroup analyses}

Subgroup analyses based upon type of lithotripsy (EHL versus LL) were also performed with results highlighted in $>$ Table 3. Technical success rate was lower for EHL compared to LL [85.92\% (95\% Cl 66.35 to $\left.94.97 ; I^{2}=61.30\right)$ versus $97.74 \%$ (95\% Cl 92.42 to $\left.99.35 ; I^{2}=0.00\right) ; P=0.0509$ ] though this was not statistically significant (Supplemental Fig.1a). Overall stone fragmentation rate was not statistically different between EHL versus LL [76.16\% $\left(95 \% \mathrm{Cl} 55.61\right.$ to $89.07 ; \mathrm{I}^{2}=$ 61.19 ) versus $96.32 \%$ (95\% Cl 82.88 to $\left.99.30 ; I^{2}=48.68\right) ; P=$ 0.1430] (Supplemental Fig. 1b). Single session POP with lithotripsy success rates were also similar for EHL compared to LL [46.18\% (95\% Cl 20.96 to $\left.73.52 ; r^{2}=69.67\right)$ versus $60.49 \%$ (95\% Cl 25.28 to 87.39; $I^{2}=90.64$ ); $P=0.5573$ ] (Supplemental Fig. 1c). The rate of total AEs was also similar between the two groups [EHL: $10.24 \%\left(95 \% \mathrm{Cl} 4.60\right.$ to $\left.21.26 ; \mathrm{I}^{2}=0.00\right)$ versus $\mathrm{LL}$ : $7.09 \%\left(95 \% \mathrm{Cl} 3.59\right.$ to $\left.13.54 ; I^{2}=0.00\right) ; P=0.4542$ ] (Supplemental Fig. 1d). A summary of technical success, fragmentation rate, single-session lithotripsy success, and AEs for POP-assisted lithotripsy is highlighted in $>$ Table 3 . 


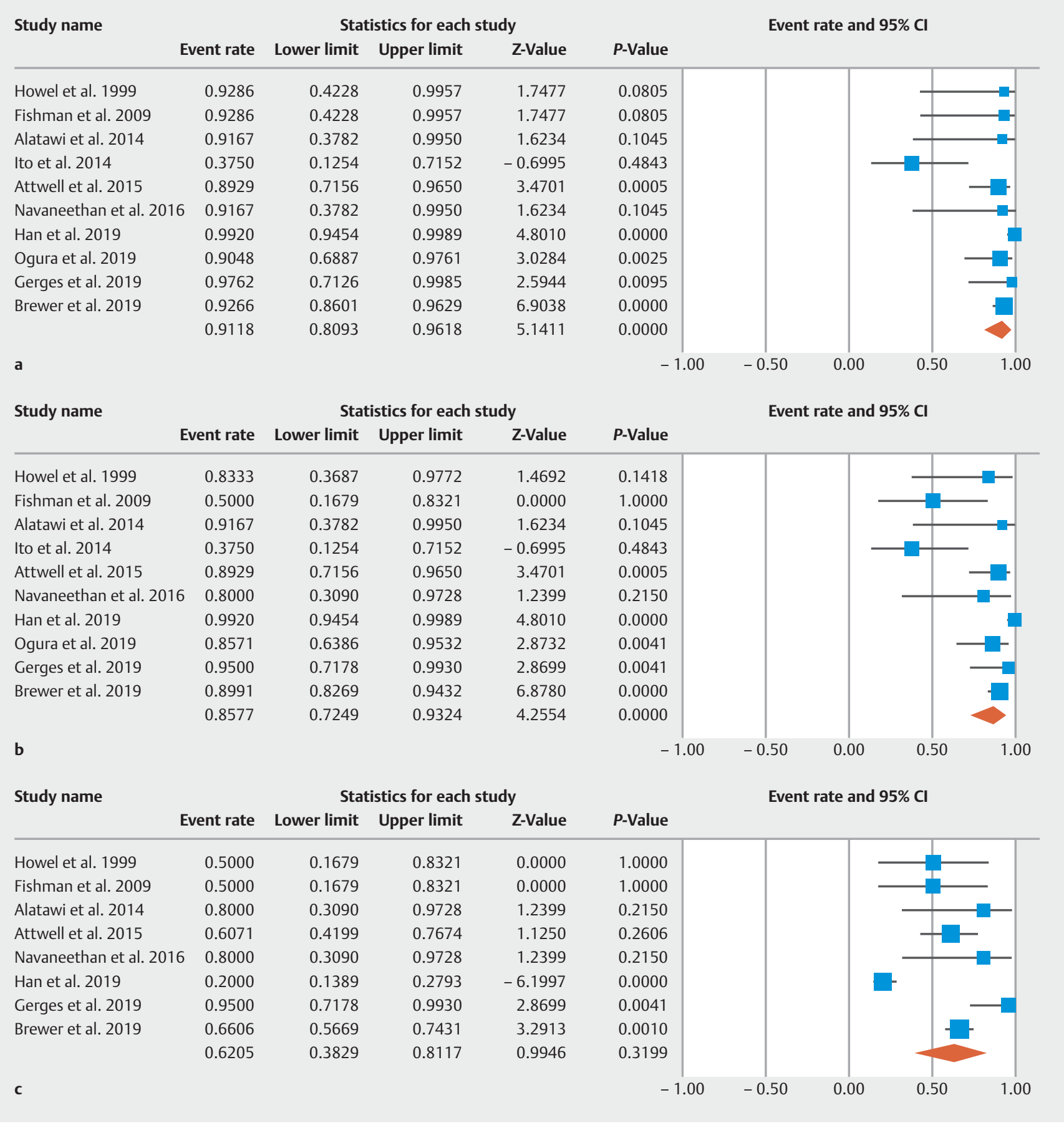

- Fig. 2 a Technical success rate of per-oral pancreatoscopy with intraductal lithotripsy for difficult pancreatic duct stones. b Overall fragmentation success rate of per-oral pancreatoscopy with intraductal lithotripsy for difficult pancreatic duct stones. c Single session complete fragmentation success rate of per-oral pancreatoscopy with intraductal lithotripsy for difficult pancreatic duct stones.

\section{Risk of bias assessment}

All observation studies were evaluated using the Newcastle-Ottawa Quality Assessment Scale scores. Quality assessment for each study shown in $>$ Table 1 . All included studies were considered to be of high quality with Newcastle-Ottawa Quality Assessment Scale scores $\geq 4$. Publication bias was also assessed. Visual inspection of the funnel plot demonstrated that smaller and statistically insignificant studies appeared to be missing likely due to publication bias ( $\triangleright$ Fig.4a). With the Duval and Tweedie's trim and fill method, overall technical success of POP with intraductal lithotripsy was slightly decreased from $92.97 \%(95 \% \mathrm{Cl}, 84.00$ to 97.09$)$ to $84.67 \%(95 \% \mathrm{Cl} 68.85$ to 93.24) though this was not statistically significant ( $\bullet$ Fig.4b). 


\begin{tabular}{|c|c|c|c|c|c|c|c|c|c|}
\hline \multirow[t]{2}{*}{ Study name } & \multicolumn{5}{|c|}{ Statistics for each study } & \multicolumn{4}{|c|}{ Event rate and $95 \% \mathrm{Cl}$} \\
\hline & Event rate & \multirow{2}{*}{$\begin{array}{r}\text { Lower limit } \\
0.0228\end{array}$} & \multirow{2}{*}{$\begin{array}{r}\text { Upper limit } \\
0.6313\end{array}$} & \multirow{2}{*}{$\begin{array}{r}\text { Z-Value } \\
-1.4692\end{array}$} & \multicolumn{5}{|l|}{ P-Value } \\
\hline Howel et al. 1999 & 0.1667 & & & & 0.1418 & & & & \\
\hline Fishman et al. 2009 & 0.0714 & 0.0043 & 0.5772 & -1.7477 & 0.0805 & & & & \\
\hline Alatawi et al. 2014 & 0.0833 & 0.0050 & 0.6218 & -1.6234 & 0.1045 & & & & \\
\hline Ito et al. 2014 & 0.2500 & 0.0630 & 0.6229 & -1.3455 & 0.1785 & & & & \\
\hline Attwell et al. 2015 & 0.2857 & 0.1498 & 0.4759 & -2.1904 & 0.0285 & & & & \\
\hline Navaneethan et al. 2016 & $5 \quad 0.0833$ & 0.0050 & 0.6218 & -1.6234 & 0.1045 & & & & \\
\hline Han et al. 2019 & 0.0640 & 0.0323 & 0.1228 & -7.3411 & 0.0000 & & & & \\
\hline Ogura et al. 2019 & 0.0476 & 0.0067 & 0.7214 & -2.9235 & 0.0035 & & & & \\
\hline Gerges et al. 2019 & 0.3043 & 0.1525 & 0.5154 & -1.8242 & 0.0681 & & & & \\
\hline \multirow{2}{*}{ Brewer et al. 2019} & 0.1009 & 0.0568 & 0.1731 & -6.8780 & 0.0000 & & & & \\
\hline & 0.1409 & 0.0831 & 0.2290 & -5.9688 & 0.0000 & & & & \\
\hline a & & & & & -1.00 & -0.50 & 0.00 & 0.50 & 1.00 \\
\hline \multirow[t]{2}{*}{ Study name } & \multicolumn{5}{|c|}{ Statistics for each study } & \multirow{2}{*}{\multicolumn{3}{|c|}{ Event rate and $95 \% \mathrm{Cl}$}} & \\
\hline & Event rate & Lower limit & Upper limit & Z-Value & $P$-Value & & & & \\
\hline Howel et al. 1999 & 0.1667 & 0.0228 & 0.6313 & -1.4692 & 0.1418 & & & & \\
\hline Fishman et al. 2009 & 0.0714 & 0.0043 & 0.5772 & -1.7477 & 0.0805 & & - & & \\
\hline Alatawi et al. 2014 & 0.0833 & 0.0050 & 0.6218 & -1.6234 & 0.1045 & & & & \\
\hline Ito et al. 2014 & 0.2500 & 0.0630 & 0.6229 & -1.3455 & 0.1785 & & & & \\
\hline Attwell et al. 2015 & 0.0172 & 0.0011 & 0.2232 & -2.8341 & 0.0046 & & & & \\
\hline Navaneethan et al. 2016 & $5 \quad 0.0833$ & 0.0050 & 0.6218 & -1.6234 & 0.1045 & & & & \\
\hline Han et al. 2019 & 0.0080 & 0.0011 & 0.0546 & -4.8010 & 0.0000 & & & & \\
\hline Ogura et al. 2019 & 0.0227 & 0.0014 & 0.2774 & -2.6292 & 0.0086 & & & & \\
\hline Gerges et al. 2019 & 0.0435 & 0.0061 & 0.2522 & -3.0231 & 0.0025 & & & & \\
\hline \multirow[t]{2}{*}{ Brewer et al. 2019} & 0.0183 & 0.0046 & 0.0704 & -5.5762 & 0.0000 & & & & \\
\hline & 0.0484 & 0.0213 & 0.1062 & -6.8765 & 0.0000 & & $\nabla$ & & \\
\hline b & & & & & -1.00 & -0.50 & 0.00 & 0.50 & 1.00 \\
\hline \multirow[t]{2}{*}{ Study name } & \multicolumn{5}{|c|}{ Statistics for each study } & \multirow{2}{*}{\multicolumn{3}{|c|}{ Event rate and $95 \% \mathrm{Cl}$}} & \\
\hline & Event rate & Lower limit & Upper limit & Z-Value & $P$-Value & & & & \\
\hline Howel et al. 1999 & 0.0714 & 0.0043 & 0.5772 & -1.7477 & 0.0805 & & & & \\
\hline Fishman et al. 2009 & 0.0714 & 0.0043 & 0.5772 & -1.7477 & 0.0805 & & & & \\
\hline Alatawi et al. 2014 & 0.0833 & 0.0050 & 0.6218 & -1.6234 & 0.1045 & & & & \\
\hline Ito et al. 2014 & 0.1250 & 0.0173 & 0.5373 & -1.8202 & 0.0687 & & $\rightarrow$ & & \\
\hline Attwell et al. 2015 & 0.0357 & 0.0050 & 0.2142 & -3.2364 & 0.0012 & & & & \\
\hline Navaneethan et al. 2016 & $5 \quad 0.0833$ & 0.0050 & 0.6218 & -1.6234 & 0.1045 & & & & \\
\hline Ogura et al. 2019 & 0.0476 & 0.0067 & 0.2714 & -2.9235 & 0.0035 & & 든 & & \\
\hline Gerges et al. 2019 & 0.2609 & 0.1222 & 0.4723 & -2.1932 & 0.0283 & & & & \\
\hline \multirow[t]{2}{*}{ Brewer et al. 2019} & 0.0459 & 0.0192 & 0.1055 & -6.6289 & 0.0000 & & & & \\
\hline & 0.0873 & 0.0450 & 0.1627 & -6.4871 & 0.0000 & & & & \\
\hline c & & & & & -1.00 & -0.50 & 0.00 & 0.50 & 1.00 \\
\hline
\end{tabular}

- Fig. 3 a Total adverse event rate of per-oral pancreatoscopy with intraductal lithotripsy for difficult pancreatic duct stones. b Serious adverse event rate of per-oral pancreatoscopy with intraductal lithotripsy for difficult pancreatic duct stones. c Post-ERCP adverse event rate of per-oral pancreatoscopy with intraductal lithotripsy for difficult pancreatic duct stones.

\section{Discussion}

While pancreatic duct stones are a common sequelae of chronic pancreatitis, intraductal stones also may result in recurrent episodes of acute pancreatitis or exacerbations of abdominal pain if they become obstructed within the pancreatic duct. Over the course of the last several decades, ERCP with sphincterotomy with pancreatic stent placement if a stricture is present, and use of ESWL have been the mainstay diagnostic and therapeutic modality to manage symptomatic pancreatic duct stones, particularly large or difficult to remove stones. A small, albeit significant, percentage of patients fail to respond to conventional pancreatic stone extraction techniques and require additional therapy. Based upon the results of this meta-analysis, POP 
Table 3 Efficacy and safety of per-oral pancreatoscopy: electrohydraulic lithotripsy versus laser lithotripsy.

\begin{tabular}{|c|c|c|c|c|c|}
\hline & \multicolumn{2}{|c|}{ Electrohydraulic Lithotripsy (EHL) } & \multicolumn{2}{|l|}{ Laser Lithotripsy (LL) } & \multirow[t]{2}{*}{$P$ value } \\
\hline & $\begin{array}{l}\text { Pooled Rate } \\
(95 \% \mathrm{Cl})\end{array}$ & $\begin{array}{l}\text { Heterogeneity } \\
\left(I^{2}\right)\end{array}$ & $\begin{array}{l}\text { Pooled Rate } \\
(95 \% \mathrm{Cl})\end{array}$ & $\begin{array}{l}\text { Heterogeneity } \\
\left(I^{2}\right)\end{array}$ & \\
\hline Technical Success (\%) & $\begin{array}{l}85.92 \% \\
(95 \% \mathrm{Cl} 66.35 \text { to } 94.97) \\
{[6 \text { studies, } n=124 \text { ] }}\end{array}$ & 61.30 & $\begin{array}{l}97.74 \% \\
(95 \% \mathrm{Cl} 92.42 \text { to } 99.35) \\
{[4 \text { studies, } n=161]}\end{array}$ & 0.00 & 0.0509 \\
\hline Clinical Success (\%) & $\begin{array}{l}76.16 \% \\
(95 \% \mathrm{Cl} 55.61 \text { to } 89.07) \\
{[5 \text { studies, } n=44 \text { ] }}\end{array}$ & 61.19 & $\begin{array}{l}96.32 \% \\
(95 \% \mathrm{Cl} 82.88 \text { to } 99.30) \\
{[3 \text { studies, } n=111]}\end{array}$ & 48.68 & 0.1430 \\
\hline Single Lithotripsy Success (\%) & $\begin{array}{l}46.18 \% \\
(95 \% \mathrm{Cl} 20.96 \text { to } 73.52) \\
{[3 \text { studies, } \mathrm{n}=36 \text { ] }}\end{array}$ & 69.67 & $\begin{array}{l}60.49 \% \\
(95 \% \mathrm{Cl} 25.28 \text { to } 87.39) \\
{[3 \text { studies, } \mathrm{n}=111 \text { ] }}\end{array}$ & 90.64 & 0.5573 \\
\hline Adverse Events (\%) & $\begin{array}{l}10.24 \% \\
(95 \% \mathrm{Cl} 4.60 \text { to } 21.26) \\
{[6 \text { studies, } \mathrm{n}=71 \text { ] }}\end{array}$ & 0.00 & $\begin{array}{l}7.09 \% \\
(95 \% \mathrm{Cl} 3.59 \text { to } 13.54) \\
{[3 \text { studies, } \mathrm{n}=111]}\end{array}$ & 0.00 & 0.4542 \\
\hline
\end{tabular}

with intraductal lithotripsy, including both EHL and LL, was highly effective and safe for difficult to remove pancreatic duct stones. Despite included patients undergoing previous treatment for attempted stone removal, the overall stone fragmentation success of pancreatoscopy-assisted intraductal lithotripsy was $85.77 \%$ with serious adverse events reported in only $4.84 \%$ of cases.

\section{Advantages, disadvantages of per-oral pancreatoscopy}

POP-assisted therapy has several distinct advantages over traditional ERCP stone extraction methods. In addition to use as an adjunctive therapy, pancreatoscopy allows for improved maneuverability to directly locate, visualize, and treat pancreatic duct stones; direct visualization to reduce duct injury, confirm ductal clearance, plus assess for residual stones after stone extraction; and may even detect pancreatic duct stones previously missed on high-resolution imaging such as magnetic resonance [37-39]. Limitations or disadvantages of per-oral pancreatoscopy include significant cost, the need for expertise or familiarity with the device to achieve cannulation and access to the pancreatic duct, need for sufficient diameter of the pancreatic duct due to diameter of the pancreatoscope, long duration of procedure compared to other strategies, and moderate success rates of conventional strategies $[40,41]$.

\section{Comparison of intraductal therapies}

Although both EHL and LL both attempt to fragment pancreatic duct stones, the process of achieving this is fundamentally different between the two strategies. EHL uses two coaxially insulated electrodes to generate high-amplitude hydraulic pressure waves to accomplish stone fragmentation, while laser lithotripsy utilizes a laser beam with repetitive pulses of laser energy to create a mechanical shockwave $[42,43]$. Evaluation of the two modalities independently resulted in LL demonstrating a trend towards superior technical and clinical efficacy and safety as compared to EHL, though this was not statistically significant based upon meta-regression subgroup analyses. Technical success, fragmentation success, single session duct clearance, and adverse events were not different between EHL and LL as evidenced by the overlapping confidence intervals.

\section{Current guidelines and expert consensus statements}

Based upon recently published guidelines in 2019, the European Society of Gastrointestinal Endoscopy (ESGE) currently does not support use of POP-assisted intraductal lithotripsy (EHL or LL) as a treatment option for symptomatic pancreatic duct stones due to sparse data [44]. However, based upon this systematic review and meta-analysis, future guidelines may propose an increased role for POP - especially among symptomatic patients that may have refractory stones. While anecdotal experience and clinical practice patterns may suggest that $L L$ is preferable to EHL if POP is undertaken, this systematic review and meta-analysis demonstrated there was no statistical difference based upon performance measures - though we acknowledge more prospective comparator studies are needed. Excluding important variables such as cost, interoperator variability, and endoscopist or center familiarity, our results may be interpreted that POP with intraductal lithotripsy, regardless of EHL or $\mathrm{LL}$, is an effective and safe treatment for refractory pancreatic duct stones.

\section{Strengths and limitations}

Specific limitations to this study include moderate-to-significant heterogeneity of included studies, including differences in patient population, lack of long-term follow-up periods, varied sizes and locations of pancreatic stones, previous attempted treatments, multiple POP techniques, as well as interoperator procedural capability and familiarity. Furthermore, no randomized trials or prospective studies were included in this analysis with a complete reliance upon small sample size retrospective observational data. In addition, fragmentation success may be less relevant to clinicians when compared to clinical im- 

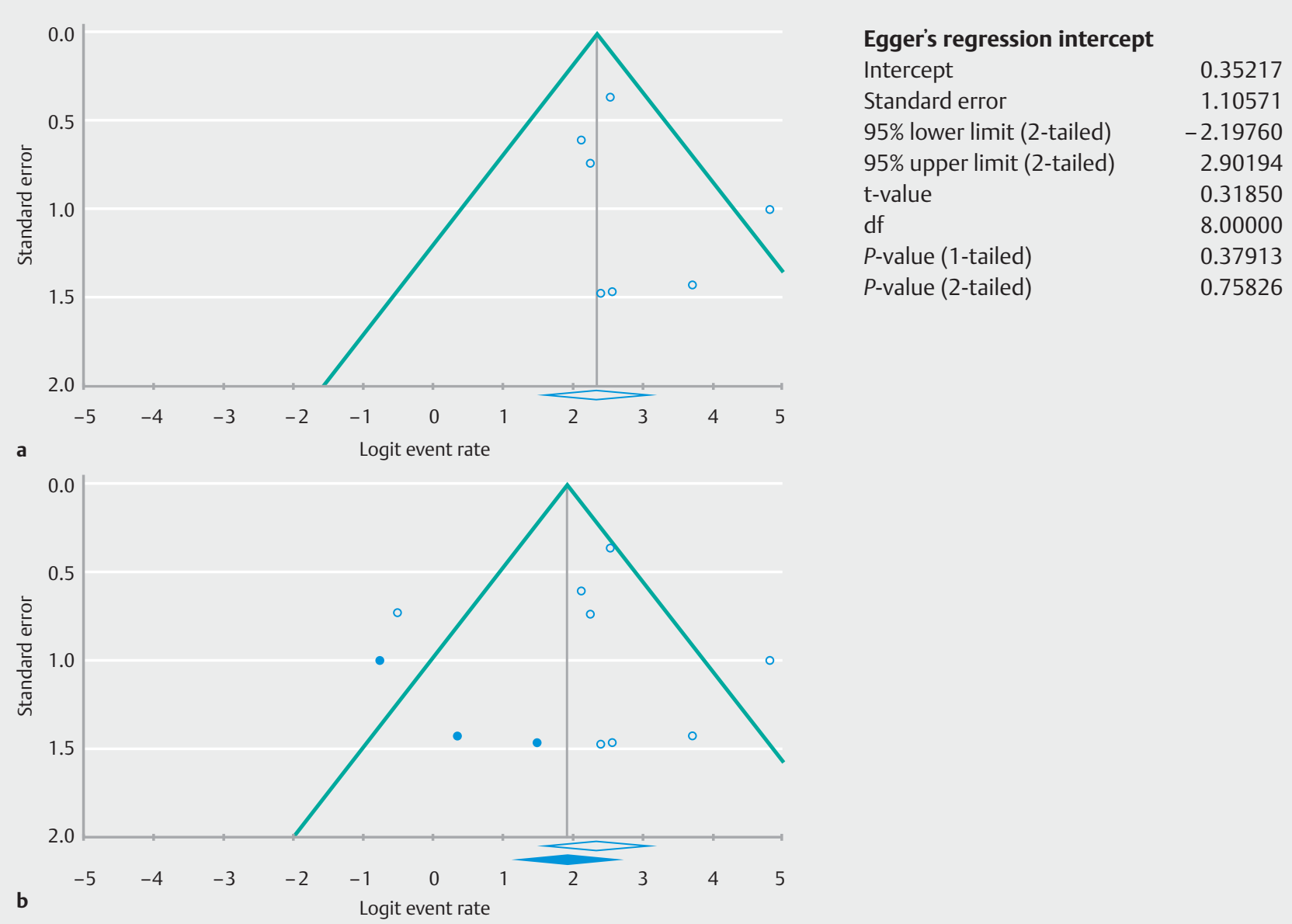

- Fig. 4 a Funnel plot of publication bias and eggers regression test for included studies. b Funnel plot of publication bias with Duval and Tweedie's trim and fill method.

provement (clinical success) as a measure of procedural success. Publication bias was also assessed and present in a metaanalysis; however, correction of such did not significantly alter our findings. Due to style of reporting, a subgroup analysis to evaluate efficacy and safety by stone location was also not possible though may be exceedingly important for planning future procedures. An additional concern with any endoscopic procedure or technique is the learning curve or clinical expertise needed to perform an effective procedure. It is highly possible the fragmentation success achieved in these studies as well as the rate of adverse events may not be generalizable to centers with less familiarity or proven expertise.

Despite these limitations, this study has several strengths. Most importantly, our meta-analysis methodologically summarizes all available data to evaluate the feasibility, efficacy, and tolerability of the POP procedure. While significant heterogeneity was noted in our meta-analysis and was not surprising given the cumulative nature of reporting results, this is the first systematic review and meta-analysis to POP-EHL and POP-LL for pancreatic duct stones to these authors' knowledge. Overall, POP was demonstrated to be an effective modality for symptomatic pancreatic duct stones with sensitivity and subgroup a- nalysis with meta-regression performed to simulate up to date clinical practice and inform important next-steps in management (i. e., the potential decision between using EHL or laser lithotripsy among patients that may have failed more traditional approaches). We hope these findings provide an important step forward in future research and impact clinical decision making among advanced endoscopists.

\section{Conclusion}

The results of this systematic review and meta-analysis suggest that POP with intraductal lithotripsy is a highly effective and safe therapy for patients with symptomatic pancreatic duct stones. When compared to EHL, LL was associated with a generally higher technical and overall fragmentation success rate and better single-session fragmentation success; however, these differences were not statistically significant and larger controlled studies are needed for direct comparison and cost-effective analysis. Overall, POP with intraductal lithotripsy provides a valuable tool for endoscopists in the treatment of difficult pancreatic duct stones that may not have responded to previous endoscopic treatment. 


\section{Competing interests}

Dr. Rustagi is a consultant for Boston Scientific and Cook Endoscopy.

References

[1] Steer ML, Waxman I, Freedman S. Chronic pancreatitis. N Engl J Med 1995; 332: 1482-1490

[2] Mitchell RM, Byrne MF, Baillie J. Pancreatitis. Lancet 2003; 361: 14471455

[3] Kloppel G. Pathology of chronic pancreatitis and pancreatic pain. Acta Chir Scand 1990; 156: 261-265

[4] Choi EK, Lehman GA. Update on endoscopic management of main pancreatic duct stones in chronic calcific pancreatitis. Korean J Intern Med 2012; 27: 20-29

[5] Ammann RW, Muench R, Otto R et al. Evolution and regression of pancreatic calcification in chronic pancreatitis. A prospective longterm study of 107 patients. Gastroenterology 1988; 95: 1018-1028

[6] Sherman S, Lehman GA, Hawes RH et al. Pancreatic ductal stones: frequency of successful endoscopic removal and improvement in symptoms. Gastrointest Endosc 1991; 37: 511-517

[7] Adamek HE, Jakobs R, Buttmann A et al. Long term follow up of patients with chronic pancreatitis and pancreatic stones treated with extracorporeal shock wave lithotripsy. Gut 1999; 45: 402-405

[8] Kim YH, Jang SI, Rhee K et al. Endoscopic treatment of pancreatic calculi. Clin Endosc 2014; 47: 227-235

[9] Dumonceau JM, Delhaye M, Tringali A et al. Endoscopic treatment of chronic pancreatitis: European Society of Gastrointestinal Endoscopy (ESGE) Guideline - Updated August 2018. Endoscopy 2019; 51: 179193

[10] Dumonceau JM, Delhaye M, Tringali A et al. Endoscopic treatment of chronic pancreatitis: European Society of Gastrointestinal Endoscopy (ESGE) Clinical Guideline. Endoscopy 2012; 44: 784-800

[11] Liberati A, Altman DG, Tetzlaff J. The PRISMA statement for reporting systematic reviews and meta-analyses of studies that evaluate health care interventions: explanation and elaboration. Ann Internal Med 2009; 151: W65-W94

[12] Stroup DF, Berlin JA, Morton SC et al. Meta-analysis of observational studies in epidemiology: a proposal for reporting. Meta-analysis Of Observational Studies in Epidemiology (MOOSE) group. JAMA 2000; 283: 2008-2012

[13] Der Simonian R, Laird N. Meta-analysis in clinical trials. Controlled Clin Trials 1986; 7: 177-188

[14] Stuart A, Ord JK. Kendall's Advanced Theory of Statistics. 6th ed. London: Edward Arnold; 1994

[15] Riley RD, Higgins JP, Deeks JJ. Interpretation of random effects metaanalyses. BMJ 2011; 342: d549

[16] Higgins JP, Thompson SG, Deeks J] et al. Measuring inconsistency in meta-analyses. BMJ 2003; 327: 557-560

[17] Overton RC. A comparison of fixed-effects and mixed (random-effects) models for meta-analysis tests of moderator variable effects. Psychological Methods 1998; 3: 354-379

[18] Wells G, Shea B et al. The Newcastle-Ottawa Scale (NOS) for assessing the quality of nonrandomised studies in meta-analysis. Oxford: 3rd Symposium on Systematic Reviews: Beyond the Basics. July 3-5 2000; 2000: Available at (Accessed 24 April 2019): http://www.ohri.ca/ programs/clinical_epidemiology/oxford.asp

[19] Jadad AR, Moore RA, Carroll D et al. Assessing the quality of reports of randomized clinical trials: is blinding necessary. Control Clin Trials 1996; 17: 1-12
[20] Borenstein M, Higgins JP, Hedges LV et al. Basics of meta-analysis: I(2) is not an absolute measure of heterogeneity. Res Synth Methods 2017; 8: 5-18

[21] Mohan BP, Adler DG. Heterogeneity in systematic review and metaanalysis: how to read between the numbers. Gastrointest Endosc 2019; 89: 902-903

[22] Borenstein M, Hedges LV, Higgins JP et al. Introduction to meta-analysis. Hoboken: John Wiley \& Sons; 2011

[23] Higgins J, Thompson SG, Spiegelhalter DJ. A re-evaluation of randomeffects meta-analysis. J R Statist Soc A 2009; 172: 137-159

[24] Egger M, Davey Smith G, Schneider M et al. Bias in meta-analysis detected by a simple, graphical test. BMJ 1997; 315: 629-634

[25] Easterbrook PJ, Berlin JA, Gopalan R et al. Publication bias in clinical research. Lancet 1991; 337: 867-872

[26] Duval S, Tweedie R. Trim and fill: a simple funnel-plot-based method of testing and adjusting for publication bias in metaanalysis. Biometrics 2000; 56: 455-463

[27] Howell DA, Dy RM, Hanson BL et al. Endoscopic treatment of pancreatic duct stones using a $10 \mathrm{~F}$ pancreatoscope and electrohydraulic lithotripsy. Gastrointest Endosc 1999; 50: 829-833

[28] Fishman DS, Tarnasky PR, Patel SN et al. Management of pancreaticobiliary disease using a new intra-ductal endoscope: the Texas experience. World J Gastroenterol 2009; 15: 1353-1358

[29] Alatawi A, Leblanc S, Vienne A et al. Pancreatoscopy-guided intracorporeal laser lithotripsy for difficult pancreatic duct stones: a case series with prospective follow-up (with video). Gastrointest Endosc 2013; 78: 179-183

[30] Attwell AR, Patel S, Kahaleh M et al. ERCP with per-oral pancreatoscopy-guided laser lithotripsy for calcific chronic pancreatitis: a multicenter U.S. experience. Gastrointest Endosc 2015; 82: 311-318

[31] Ito K, Igarashi Y, Okano $\mathrm{N}$ et al. Efficacy of combined endoscopic lithotomy and extracorporeal shock wave lithotripsy, and additional electrohydraulic lithotripsy using the SpyGlass direct visualization system or X-ray guided EHL as needed, for pancreatic lithiasis. Biomed Res Int 2014; 2014: 732781

[32] Navaneethan U, Hasan MK, Kommaraju K et al. Digital, single-operator cholangiopancreatoscopy in the diagnosis and management of pancreatobiliary disorders: a multicenter clinical experience (with video). Gastrointest Endosc 2016; 84: 649-655

[33] Brewer Gutierrez OI, Raijman I, Shah RJ et al. Safety and efficacy of digital single-operator pancreatoscopy for obstructing pancreatic ductal stones. Endosc Int Open 2019; 7: E896-E903

[34] Gerges C, Pullmann D, Bahin F et al. SpyGlass DS-guided lithotripsy for pancreatic duct stones in symptomatic treatment-refractory chronic calcifying pancreatitis. Endosc Int Open 2019; 7: E99-E103

[35] Han S, Shah RJ, Brauer BC et al. A comparison of endoscopic retrograde pancreatography with or without pancreatoscopy for removal of pancreatic duct stones. Pancreas 2019; 48: 690-697

[36] Ogura T, Okuda A, Imanishi M et al. Electrohydraulic lithotripsy for pancreatic duct stones under digital single-operator pancreatoscopy (with video). Dig Dis Sci 2019; 64: 1377-1382

[37] Awadallah NS, Chen YK, Piraka C et al. Is there a role for cholangioscopy in patients with primary sclerosing cholangitis? Am J Gastroenterol 2006; 101: 284-291

[38] Ramchandani M, Reddy DN, Lakhtakia S et al. Per oral cholangiopancreatoscopy in pancreatico biliary diseases-expert consensus statements. World J Gastroenterol 2015; 21: 4722-4734

[39] Xu MM, Kahaleh M. Recent developments in choledochoscopy: technical and clinical advances. Clin Exp Gastroenterol 2016; 9: 119-124

[40] Karagyozov P, Boeva I, Tishkov I. Role of digital single-operator cholangioscopy in the diagnosis and treatment of biliary disorders. World J Gastrointest Endosc 2019; 11: 31-40 
[41] Parsi MA. Direct peroral cholangioscopy. World J Gastrointest Endosc 2014; 6: 1-5

[42] Sievert CE Jr., Silvis SE. Evaluation of electrohydraulic lithotripsy as a means of gallstone fragmentation in a canine model. Gastrointest Endosc 1987; 33: 233-235
[43] Hochberger ], Gruber E, Wirtz P et al. Lithotripsy of gallstones by means of a quality-switched giant-pulse neodymium:yttrium-aluminum-garnet laser. Basic in vitro studies using a highly flexible fiber system. Gastroenterology 1991; 101: 1391-1398

[44] Manes G, Paspatis G, Aabakken L et al. Endoscopic management of common bile duct stones: European Society of Gastrointestinal Endoscopy (ESGE) guideline. Endoscopy 2019; 51: 472-491 